\title{
Performance Evaluation of Religious Funds
}

\author{
Praveen Das ${ }^{1}$, S. P. Uma Rao ${ }^{1} \&$ Denis Boudreaux ${ }^{1}$ \\ ${ }^{1}$ B. I. Moody III College of Business Administration, University of Louisiana at Lafayette, USA \\ Correspondence: Praveen Das, B. I. Moody III College of Business Administration, University of Louisiana at \\ Lafayette, USA. Tel: 1-337-482-6656.
}

Received: January 27, 2016

Accepted: May 12, 2016

Online Published: October 26, 2017

doi:10.5430/ijfr.v8n4p240

URL: https://doi.org/10.5430/ijfr.v8n4p240

\begin{abstract}
This exploratory study uses monthly net return data from August 2008 to June 2015 on 5 actively managed religious funds to distinguish between luck and skill of fund managers. The main benchmark of this study is the Fama-French-five-factor-model (2013). First, the abnormal performance, alpha, $\alpha \mathrm{i}$, of the equally weighted mutual fund with the above five factor model is examined. Second, we use the bootstrapping simulation approach of Fama and French (2010), to separate manager's skill from luck. Equally weighted fund exhibits skill.
\end{abstract}

Keywords: religious funds, faith-based, Fama and French, Boot-strapping, luck, skill, fund performance, active, passive, fund management, five-factor model

\section{Introduction}

Mutual fund investors focus particularly in the tails of performance distribution and are mainly interested to identify very good performers for investing or very bad performers to avoid. We find that standard, straightforward and simple multi-factor performance measures used in previous mutual fund studies have little ability to detect whether the positive or negative risk-adjusted abnormal performance (the "alpha") is due to skill or luck. The general consensus of mutual fund research is that restrictions placed on the screening criteria for stocks, result in less than optimal performance. So, as a test case, we choose a sample of five religious funds with restrictive screening. An equally-weighted fund is created out of these five funds and this equally-weighted fund has long-term superior performance based on a well-known performance evaluation technique: Fama-French-five-factor-model (2013). Then we use 1,000 simulations to apply the bootstrap-methodology with true alpha set to zero (i.e., assuming that fund has no stock picking ability). This helps us to determine whether or not manager/managers of this superior performing fund are skilled or lucky.

Kosowski et al. (2006) were among the first to apply the bootstrap method to mutual fund performance. This latest methodology was never applied before to religious funds. The bootstrap approach - as opposed to persistence studies has several advantages, such as no assumptions are made about the distribution of returns and alphas of funds, and also a long-time series of performance can be used. In this study, we are able to separate 'skill' from 'luck' in the performance of equally-weighted religious funds, even when the distribution of idiosyncratic risk is highly non-normal. Our study provides new evidence on the abnormal performance measure of the religious funds and our paper's results are not easily inferred from other studies. Applying multi-factor model to a mutual fund involves considerations whose potential consequences cannot easily be studied without using longer time-series bootstrap simulations. Our study uses longer time series of performance.

\section{Literature Review}

Past academic studies of US mutual funds show little evidence of positive abnormal performance but present stronger evidence of poor performing funds. The evidence is not entirely definitive. Though several researchers document negative average fund alphas on a style adjusted basis, net of expenses and trading costs (see, Carhart (1997)), Christopherson et al (1998), and Hendricks et al (1993)) recent papers indicate that some fund managers have stock-selection skills. For example, Kosowski, Timmermann, Wermers, and White (2006) use a bootstrap technique to document outperformance by some funds. Avramov and Wermers (2006) show the benefits of investing in actively-managed funds from a Bayesian perspective. Cuthbertson et al. (2008) used data on UK equity funds from 1976 to 2002 and found an existence of stock picking ability among a small number of the top performing funds that they concluded was not solely due to luck. They also found that the underperforming funds demonstrate bad skill. Cuthbertson et al. concluded that for the majority of funds, positive abnormal performance could be attributed to good luck. 
No study of religious funds so far has focused on measuring whether the realized performance was driven by skill or mere luck. This paper separates skill from luck in religious fund managers' investment performance by using a five factor model developed by Fama and French and apply the latest bootstrapping simulations methodology. Using this bootstrap technique we examine the performance of an equally-weighted Fund of five religious funds over the August 2008 through June 2015 period. We set alpha equal to zero under the hypothesis of pure luck and then compare it to actual observed performance.

\section{Methodology}

In 2013, Fama and French introduced a five-factor asset pricing model, adding profitability and investment factors to augment the three-factor model.

$$
R i t-R F t=\alpha i+b i(R M t-R F t)+s i S M B t+h i H M L t+r i R M W t+c i C M A t+e i t .
$$

In this equation $R M W t$ is the difference between the returns on diversified portfolios of stocks with robust and weak profitability, and CMAt is the difference between the returns on diversified portfolios of low and high investment stocks, which are called conservative and aggressive. If the sensitivities to the five factors, $b i, s i, h i, r i$, and $c i$, capture all variation in expected returns, the intercept aiis zero for all securities and portfolios $i$.

First, the abnormal performance, alpha, $\alpha i$, of the equally weighted mutual fund with the above five factor model is examined. A positive alpha implies that the manager has a positive impact on fund performance, and the opposite happens with a negative alpha.

Second, we use the bootstrapping simulation approach of Fama and French (2010), to separate manager's skill from luck. Following are the steps taken by this study: First, $\alpha$ and its t-statistic for the equally-weighted portfolio are estimated from five-factor Fama-French model. We subtract the estimated $\alpha$ from the mutual fund's monthly returns to generate adjusted return series with true true $\alpha$ of zero. Then, a random draw from these adjusted returns 83 times (with replacement) generated new return series per simulation run. Next, we estimate a new simulated $\alpha$ and $t(\alpha)$ per portfolio in each simulation. So, in this "no skill" (true alpha=0) simulation, the distribution of estimated alphas should always stick at zero.The estimated $\alpha$ value significantly differently from zero is suggests 'luck' factor. Finally the $t(\alpha)$ value at each percentile is computed as an average of the percentile values from all 1000 simulation runs.

Following Kosowski et al. (2006), Fama and French (2010) as well as Barras et al. (2010), we use the t-statistics of $\alpha$, $t(\alpha)$, instead of $\alpha$ for the analysis. The distribution of the actual $t(\alpha)$ and the simulated $t(\alpha)$ are then compared to infer whether the actual distribution is generated by mere luck or whether some manager exhibits skill.

\section{Data}

The monthly data used for this study came from Morningstar Database and was from August 2008 through June 2015, a total period of 83 months.

For this study we consider Religious funds that invest according to a set of faith-based religious principles. Carolyn Bigda of Kiplinger's Personal Finance highlights five religious funds that do not levy sales loads and have delivered solid returns despite their investing constraints. These funds are shown in Table 1. Gross expense ratios for AMANX, AVEFX, AVEDX, ETGLX and AQEIX are respectively $1.15 \%, 0.55 \%, 0.93 \%, 1.45 \%$ and $1.5 \%$ with an average of $1.116 \%$.

Table 1. Sample of five religious funds

Five funds as described by the Kiplinger article are:

1. LKCM Aquinas Value (symbol AQEIX) follows the guidelines of the U.S. Conference of Catholic Bishops.

2. Ave Maria Rising Dividend (AVEDX) takes a slightly different approach to investing according to Catholic values. The fund avoids companies with ties to abortion or pornography (including hotels that offer X-rated films in guest rooms). "It is a zero-tolerance policy," says co-manager George Schwartz. (But the fund doesn't specifically ban weapons makers.)

3. Eventide Gilead (ETGLX) is beneath the broad umbrella of Christian-oriented funds. Managers Finny Kuruvilla and David Barksdale believe work done in the service of others is blessed. So they look for firms that are sensitive to shareholders as well as to internal stakeholders (such as customers and employees) and external stakeholders (communities and the environment). They won't invest in companies that profit from alcohol, gambling and other potential addictions.

4. Ave Maria Bond (AVEFX) provides a fixed-income fund option. The fund applies the same Catholic principles of its stock-owning sibling to a mostly fixed-income portfolio. 
5. A number of funds follow the principles of Islamic, or sharia, finance, including Amana Income (AMANX). Sharia bars investments in companies involved in alcohol, pork, gambling, pornography or tobacco. It also requires that investors avoid interest. One way manager Nicholas Kaiser and deputy manager Scott Klimo deal with that is to eliminate banks and companies whose total debt adds up to more than $33 \%$ of their stock market value.

\section{Results}

When excess return on, equally-weighted mutual fundis regressed on FF-5 factors for the period 8/2008 through 6/2015, Alpha is $0.155739 \%$ per month or Alpha is $1.8689 \%$ per year and T of Alpha is 2.088157. Results are shown in Table 2. The results show that the equal-weighted religious mutual fund portfolio has three-fourth exposure -close to $76 \%$ - to the market portfolio, but very little or almost no exposure to the size, value/growth returns, profitability and investment portfolio $(0.10,-0.08,-0.06$ and 0.004$)$. Moreover, the five factors capture $97.5 \%$ of the variance of month-by-month equal-weighted fund returns.

Table 2. Regression Results

Excess return on Equally Weighted Mutual fund regressed on FF-5 factors

For the period 08/2008 through 6/2015

$R i t-R F t=\alpha i+b i(R M t-R F t)+s i S M B t+h i H M L t+r i R M W t+c i C M A t+e i t$.

\begin{tabular}{lr}
\hline \multicolumn{2}{c}{ Regression Statistics } \\
\hline Multiple R & 0.9875852 \\
R Square & 0.9753245 \\
Adjusted R Square & 0.9737222 \\
Standard Error & 0.6264321 \\
Observations & 83 \\
\hline
\end{tabular}

ANOVA

\begin{tabular}{lrcccr}
\hline & $d f$ & $S S$ & $M S$ & $F$ & Significance $F$ \\
\hline Regression & 5 & 1194.325703 & 238.8651 & 608.702 & $2.2998 \mathrm{E}-60$ \\
Residual & 77 & 30.21612415 & 0.392417 & & \\
Total & 82 & 1224.541827 & & & \\
\hline
\end{tabular}

\begin{tabular}{lrrrrrr}
\hline & Coefficients & Standard Error & \multicolumn{1}{c}{ Stat } & \multicolumn{1}{c}{ P-value } & \multicolumn{1}{c}{ Lower 95\% } & \multicolumn{1}{c}{ Upper 95\% } \\
\hline Intercept & 0.1557387 & 0.074581869 & 2.088157 & 0.04009 & 0.00722719 & 0.304250143 \\
Mkt-RF & 0.7643822 & 0.018653849 & 40.97718 & $4.8 \mathrm{E}-54$ & 0.72723766 & 0.801526777 \\
SMB & 0.1002747 & 0.033428407 & 2.999685 & 0.003639 & 0.03371024 & 0.166839162 \\
HML & -0.0812035 & 0.035970838 & -2.25748 & 0.026812 & -0.1528306 & -0.009576452 \\
RMW & -0.0630874 & 0.050850863 & -1.24064 & 0.218507 & -0.1643444 & 0.038169594 \\
CMA & 0.0041076 & 0.061291279 & 0.067018 & 0.946741 & -0.1179389 & 0.126154154 \\
\hline
\end{tabular}

Summary:

Alpha is \% per month

0.155739

or Alpha is \% per year

1.8689

$\mathrm{T}$ of Alpha

2.088157

Percent rank of 2.088157

0.983166 
Now the question is, whether a mutual fund, such as this equally weighted fund with a positive alpha relative to five-factor benchmark over some measurement period, say 83 months, can be identified as a superior fund?

In Table 3, Percentiles of $\mathrm{t}($ alpha) estimates based on 1000 Simulations, with true alpha set to zero, are presented.99th percentile is 2.3267 , the value (or score), below which 99 percent of the observations may be found.

Table 3. Percentiles of $t$ (alpha) estimates for Equally-weighted fund based on 1000 Simulations With True alpha set to zero

\begin{tabular}{|c|c|}
\hline Percentile & T(alpha) on 1000 Simulations \\
\hline 1 & -2.618005197 \\
\hline 2 & -2.469242917 \\
\hline 3 & -2.1890989 \\
\hline 4 & -2.003127345 \\
\hline 5 & -1.784888138 \\
\hline 10 & -1.41942882 \\
\hline 20 & -1.026768416 \\
\hline 30 & -0.700077565 \\
\hline 40 & -0.435198886 \\
\hline 50 & -0.186713958 \\
\hline 60 & 0.070645976 \\
\hline 70 & 0.357186695 \\
\hline 80 & 0.735234589 \\
\hline 90 & 1.278628253 \\
\hline 95 & 1.578980767 \\
\hline 96 & 1.684952013 \\
\hline 97 & 1.794741688 \\
\hline 98 & 1.999904235 \\
\hline 99 & 2.326772107 \\
\hline
\end{tabular}

Comparing the distribution of " $\alpha$ " estimates from the simulations to the " $\alpha$ " estimates for actual fund returns allows us to draw inferences about the existence of skilled manager. The ' $t$ ' statistic of 2.088157 of the actual estimated alpha of 0.155739 percent per month or 1.8689 percent has a percent rank of 98.3166 and as such the equally weighted fund exhibits skill.

Tables 4 through 8 show the individual mutual fund regression results for different periods of data. Fama-French 5 factors yielded better results than traditional three factors.

Table 4. Amana Income Investor

Excess return on Mutual fund regressed on FF-5 factors on 07/1986 through 6/2015

\begin{tabular}{lr}
\hline \multicolumn{2}{c}{ Regression Statistics } \\
\hline Multiple R & 0.913985 \\
R Square & 0.835369 \\
Adjusted R Square & 0.832962
\end{tabular}


Standard Error

1.421702

Observations

348

ANOVA

\begin{tabular}{lrlllr}
\hline & $d f$ & $S S$ & \multicolumn{1}{c}{$M S$} & \multicolumn{1}{c}{ Significance $F$} \\
\hline Regression & 5 & 3507.592 & 701.5184 & 347.0738 & $1.4 \mathrm{E}-131$ \\
Residual & 342 & 691.2631 & 2.021237 & & \\
Total & 347 & 4198.855 & & & \\
\hline
\end{tabular}

\begin{tabular}{lcrrrrr}
\hline & Coefficients Standard Error & \multicolumn{1}{c}{$t$ Stat } & \multicolumn{1}{l}{$P$-value } & Lower 95\% & Upper 95\% \\
\hline Intercept & -0.07035 & 0.081064 & -0.86781 & 0.386106 & -0.2298 & 0.089099 \\
Mkt-RF & 0.754824 & 0.019484 & 38.74167 & $3.9 \mathrm{E}-127$ & 0.716502 & 0.793147 \\
SMB & -0.03324 & 0.028242 & -1.17692 & 0.240046 & -0.08879 & 0.022311 \\
HML & 0.146518 & 0.037483 & 3.908955 & 0.000112 & 0.072793 & 0.220244 \\
RMW & 0.081099 & 0.039294 & 2.063878 & 0.039783 & 0.00381 & 0.158388 \\
CMA & 0.09614 & 0.055544 & 1.730895 & 0.084372 & -0.01311 & 0.20539 \\
\hline
\end{tabular}

Table 5. Ave Maria Bond

Excess return on Mutual fund regressed on FF-5 factors on 06/2003 through 6/2015

\begin{tabular}{lr}
\hline \multicolumn{2}{c}{ Regression Statistics } \\
\hline Multiple R & 0.662509 \\
R Square & 0.438918 \\
Adjusted R Square & 0.418735 \\
Standard Error & 0.774835 \\
Observations & 145 \\
\hline
\end{tabular}

ANOVA

\begin{tabular}{lrrrrr}
\hline & $d f$ & $S S$ & $M S$ & $F$ & Significance $F$ \\
\hline Regression & 5 & 65.28159 & 13.05632 & 21.74715 & $4.83 \mathrm{E}-16$ \\
Residual & 139 & 83.45132 & 0.600369 & & \\
Total & 144 & 148.7329 & & & \\
\hline
\end{tabular}

\begin{tabular}{lcrrrrr}
\hline & Coefficients Standard Error & \multicolumn{1}{c}{$t$ Stat } & \multicolumn{1}{c}{$P$-value } & Lower 95\% & Upper 95\% \\
\hline Intercept & 0.105669 & 0.067993 & 1.55412 & 0.12243 & -0.02876 & 0.240102 \\
Mkt-RF & 0.177922 & 0.019949 & 8.918945 & $2.43 \mathrm{E}-15$ & 0.13848 & 0.217364 \\
SMB & -0.05026 & 0.032576 & -1.54299 & 0.125106 & -0.11467 & 0.014144 \\
HML & 0.049448 & 0.03323 & 1.488065 & 0.138999 & -0.01625 & 0.115149 \\
RMW & 0.090665 & 0.051195 & 1.770976 & 0.078756 & -0.01056 & 0.191887 \\
CMA & 0.000487 & 0.054256 & 0.008973 & 0.992854 & -0.10679 & 0.10776 \\
\hline
\end{tabular}


Table 6. Ave Maria Rising Dividend

Excess return on Mutual fund regressed on FF-5 factors on 6/2005 through 6/2015

\begin{tabular}{lr}
\hline \multicolumn{2}{c}{ Regression Statistics } \\
\hline Multiple R & 0.967007 \\
R Square & 0.935103 \\
Adjusted R Square & 0.932282 \\
Standard Error & 1.045652 \\
Observations & 121 \\
\hline
\end{tabular}

ANOVA

\begin{tabular}{lrrrrr}
\hline & $d f$ & $S S$ & $M S$ & $F$ & Significance $F$ \\
\hline Regression & 5 & 1811.797 & 362.3594 & 331.4099 & $1.55 \mathrm{E}-66$ \\
Residual & 115 & 125.7395 & 1.093387 & & \\
Total & 120 & 1937.536 & & & \\
\hline
\end{tabular}

\begin{tabular}{lcrrrrr}
\hline & Coefficients Standard Error & \multicolumn{1}{c}{ Stat } & P-value & Lower 95\% & Upper 95\% \\
\hline Intercept & 0.085092 & 0.099993 & 0.85098 & 0.396549 & -0.11297 & 0.283159 \\
Mkt-RF & 0.853544 & 0.027583 & 30.94434 & $1.37 \mathrm{E}-57$ & 0.798907 & 0.908181 \\
SMB & 0.13157 & 0.047509 & 2.7694 & 0.006549 & 0.037465 & 0.225676 \\
HML & 0.168595 & 0.050504 & 3.33826 & 0.001137 & 0.068557 & 0.268634 \\
RMW & 0.193151 & 0.076205 & 2.534643 & 0.0126 & 0.042205 & 0.344098 \\
CMA & 0.060972 & 0.084776 & 0.719209 & 0.473471 & -0.10695 & 0.228897 \\
\hline
\end{tabular}

Table 7. Eventide Gilead N

Excess return on Mutual fund regressed on FF-5 factors on 8/2008 through 6/2015

\begin{tabular}{lr}
\hline \multicolumn{2}{c}{ Regression Statistics } \\
\hline Multiple R & 0.915143 \\
R Square & 0.837487 \\
Adjusted R Square & 0.826934 \\
Standard Error & 2.359213 \\
Observations & 83 \\
\hline
\end{tabular}

ANOVA

\begin{tabular}{|c|c|c|c|c|c|}
\hline & $d f$ & $S S$ & $M S$ & $F$ & Significance $F$ \\
\hline Regression & 5 & 2208.585 & 441.7171 & 79.36147 & $6.06 \mathrm{E}-29$ \\
\hline Residual & 77 & 428.5734 & 5.565888 & & \\
\hline Total & 82 & 2637.159 & & & \\
\hline
\end{tabular}

\begin{tabular}{lrrrrrr}
\hline & \multicolumn{1}{c}{ Coefficients Standard Error } & \multicolumn{1}{l}{ t Stat } & P-value & Lower 95\% & Upper 95\% \\
\hline Intercept & 0.787489 & 0.280884 & 2.803611 & 0.006392 & 0.228178 & 1.346799
\end{tabular}




\begin{tabular}{lrrrrrr} 
Mkt-RF & 0.867696 & 0.070252 & 12.35111 & $6.02 \mathrm{E}-20$ & 0.727805 & 1.007586 \\
SMB & 0.361922 & 0.125895 & 2.874788 & 0.005225 & 0.111233 & 0.612611 \\
HML & -0.41487 & 0.13547 & -3.06242 & 0.003024 & -0.68462 & -0.14511 \\
RMW & -0.82106 & 0.19151 & -4.28728 & $5.19 \mathrm{E}-05$ & -1.2024 & -0.43971 \\
CMA & -0.13009 & 0.23083 & -0.56359 & 0.574671 & -0.58973 & 0.329547 \\
\hline
\end{tabular}

Table 8. LKCM Aquinas Value

Excess return on Mutual fund regressed on FF-5 factors on 07/1986 through 6/2015

\begin{tabular}{lr}
\hline \multicolumn{2}{c}{ Regression Statistics } \\
\hline Multiple R & 0.949968 \\
R Square & 0.902439 \\
Adjusted R Square & 0.900496 \\
Standard Error & 1.388623 \\
Observations & 257 \\
\hline
\end{tabular}

ANOVA

\begin{tabular}{lrlllr}
\hline & $d f$ & $S S$ & $M S$ & $F$ & Significance $F$ \\
\hline Regression & 5 & 4476.976 & 895.3951 & 464.3506 & $1.3 \mathrm{E}-124$ \\
Residual & 251 & 483.9967 & 1.928274 & & \\
Total & 256 & 4960.972 & & & \\
\hline
\end{tabular}

\begin{tabular}{lcrrrrr}
\hline & Coefficients Standard Error & \multicolumn{1}{l}{ S Stat } & \multicolumn{1}{l}{ P-value } & Lower 95\% & Upper 95\% \\
\hline Intercept & -0.29672 & 0.093039 & -3.18925 & 0.001608 & -0.47996 & -0.11349 \\
Mkt-RF & 1.014736 & 0.023735 & 42.75243 & $3.2 \mathrm{E}-117$ & 0.967991 & 1.061482 \\
SMB & -0.00134 & 0.031579 & -0.04244 & 0.966181 & -0.06353 & 0.060852 \\
HML & 0.338152 & 0.042004 & 8.05047 & $3.31 \mathrm{E}-14$ & 0.255426 & 0.420877 \\
RMW & 0.214365 & 0.046446 & 4.615364 & $6.27 \mathrm{E}-06$ & 0.122891 & 0.305838 \\
CMA & 0.050726 & 0.059809 & 0.848127 & 0.397175 & -0.06707 & 0.168518 \\
\hline
\end{tabular}

\section{Limitations}

First, it is hard to detect abnormal performance when it exists, particularly for a fund whose style characteristics differ from those of the bench mark portfolio based on five-factor-Fama-French model. Second, if abnormal performance is short-lived (say, less than a year), the seven year results shown in Table 2 may overstate the gains. Manager's profit opportunities are more likely to be short-lived.

\section{Recommendations for Further Research}

This study used Fama-French-five-factor-model (2013) as the primary risk model. Other researchers may explore variants of this model, study a large number of different categories of funds for different time periods, and use data without any survivorship bias.

\section{Conclusion}

Common wisdom holds that the more restrictions a fund has, the more difficult it is for it to consistently perform well. This just might turn out to be a successful investing strategy. This study explores whether an equally weighted fund of religious funds, has delivered superior results despite its restrictive screens. Active management must produce returns 
large enough to offset its higher risks and fees. General consensus of investors is that managers who described themselves as active did not deserve that title, as they did little more than track an index.

A five-factor Fama-French model is utilized to capture the size, value, profitability, and investment patterns in average mutual fund returns and the resulting alpha estimate is compared to the results from 1,000 bootstrap simulations of the cross-section. The returns of the funds in a simulation run have the properties of actual fund returns, except we set true $\alpha$ to zero in the return population from which simulation samples are drawn. The simulations thus describe the distribution of " $\alpha$ " estimates when there is no abnormal performance in fund returns.

The ' $t$ ' statistic of 2.088157 of the actual estimated alpha of 0.155739 percent per month or 1.8689 percent per year, has a percent rank of 98.3166and as such the equally weighted fund exhibits skill. The fact that equally weighted fund almost beats the simulations does suggest that by picking the right funds, there is high probability that investors can outperform the market.But the problem continues to be that the good funds can't be separated from the lucky bad ones that land in the top percentiles.

\section{References}

Avramov, D., \& Wermers, R. (2006). Investing in Mutual Funds When Return are Predictable. Journal of Financial Economics, 81, 339-377. https://doi.org/10.1016/j.jfineco.2005.05.010

Barras, L., Scaillet, O., \& Wermers, R. (2010). False discoveries in mutual fund performance: Measuring luck in estimated alphas. The Journal of Finance, 65(1), 179-216. https://doi.org/10.1111/j.1540-6261.2009.01527.x

Bigda, C. (2014, October). Faith-based investing doesn't mean you have to forgo profits. Kiplinger's Personal Finance.

Carhart, M. (1997). On persistence in mutual fund performance. Journal of Finance, 52(1), 57-82. https://doi.org/10.1111/j.1540-6261.1997.tb03808.x

Christopherson, J. Ferson, \& W. Glassman, D. (1998). Conditioning Manager Alphas on Economic Information: Another Look at the Persistence of Performance. Review of Financial Studies, 11(1), 111-142. https://doi.org/10.1093/rfs/11.1.111

Cuthbertson, K., Nitzche, D., \& O'Sullivan, N. (2008). UK Mutual Fund Performance: Skill or Luck?. Journal of Empirical Finance, 15, 613-634. https://doi.org/10.1016/j.jempfin.2007.09.005

Fama, E. F., \& French, K. R. (1993). Common risk factors in the returns on stocks and bonds. Journal of Financial Economics, 33(1), 3-56. https://doi.org/10.1016/0304-405X(93)90023-5

Fama, E. F., \& French, K. R. (2010). Luck versus Skill in the Cross Section of Mutual Fund Returns. The Journal of Finance, 65(5), 1915-1947. https://doi.org/10.1111/j.1540-6261.2010.01598.x

Fama, Eugene F., \& French, Kenneth R. (2013, November). A Five-Factor Asset Pricing Model. Fama-Miller Working Paper.

Hendricks, D., Patel, J., \& Zeckhauser, R. (1993). Hot Hands in Mutual Funds: Short Run Persistence of Performance, 1974-88. Journal of Finance, 48, 93-130. https://doi.org/10.1111/j.1540-6261.1993.tb04703.x

Kosowski, R., Timmermann, A., Wermers, R., \& White, H. (2006). Can mutual fund "stars" really pick stocks? New evidence from a bootstrap analysis. The Journal of Finance, 61(6), 2551-2595. https://doi.org/10.1111/j.1540-6261.2006.01015.x 